\title{
LIQUID VENTILATION IMPROVES PULMONARY FUNCTION AND CARDIAC OUTPUT IN A NEONATAL SWINE MODEL OF CARDIOPULMONARY BYPASS
}

Ira M. Cheifetz, MD

Michael L. Cannon, MD ${ }^{\mathrm{a}}$

Damian M. Craig, MS $^{\mathrm{b}}$

George Quick ${ }^{\mathrm{b}}$

Frank H. Kern, MD ${ }^{\mathrm{a}}$

Peter K. Smith, MD ${ }^{\mathrm{b}}$

Ross M. Ungerleider, $\mathrm{MD}^{\mathrm{b}}$

Jon N. Meliones, MD
Objective: Neonatal and infant cardiopulmonary bypass results in multiorgan system dysfunction. Organ protective strategies have traditionally been directed at the myocardium and brain while neglecting the sometimes severe injury to the lungs. We hypothesized that liquid ventilation would improve pulmonary function and cardiac output in neonates after cardiopulmonary bypass. Methods: Twenty neonatal swine were randomized to receive cardiopulmonary bypass with or without liquid ventilation. In the liquid-ventilated group, a single dose of perflubron was administered before bypass. The control group was conventionally ventilated. Each animal was placed on nonpulsatile, hypothermic bypass. Low-flow cardiopulmonary bypass was performed for 60 minutes. The flow rate was returned to $125 \mathrm{ml} / \mathrm{kg}$ per minute, and after warming to $37^{\circ} \mathrm{C}$, the animals were removed from bypass. Hemodynamic and ventilatory data were obtained after bypass to assess the effects of liquid ventilation. Results: Without liquid ventilation, cardiopulmonary bypass resulted in a significant decrease in cardiac output, oxygen delivery, and static pulmonary compliance compared with prebypass values. Input pulmonary resistance and characteristic impedance increased in these control animals. At 30, 60, and 90 minutes after bypass, the animals receiving liquid ventilation showed significantly increased cardiac output and static compliance and significantly decreased input pulmonary resistance and characteristic impedance compared with control animals not receiving liquid ventilation. Conclusions: Liquid ventilation improved pulmonary function after neonatal cardiopulmonary bypass while increasing cardiac output. The morbidity associated with cardiopulmonary bypass may be significantly reduced if the adverse pulmonary sequelae of bypass can be diminished. Liquid ventilation may become an important technique to protect the lungs from the deleterious effects of cardiopulmonary bypass. (J Thorac Cardiovasc Surg 1998;115:528-35)
From the Departments of Pediatrics ${ }^{\mathrm{a}}$ and Surgery, ${ }^{\mathrm{b}}$ Duke University Medical Center, Durham, N.C.

Supported in part by a grant from the Duke Children's Hospital Miracle Network Telethon. LiquiVent was supplied by Alliance Pharmaceutical Corp. (San Diego, Calif.) and Hoechst Marion Roussel (Bridgewater, N.J.).

Read at the Seventy-seventh Annual Meeting of The American Association for Thoracic Surgery, Washington, D.C., May 4-7, 1997.

Received for publication May 5, 1997; revisions requested June 30, 1997; revisions received Oct. 23, 1997; accepted for publication Oct. 29, 1997.

Address for reprints: Ira M. Cheifetz, MD, Duke University Medical Center, Box 3046, Durham, NC 27710.

Copyright (C) 1998 by Mosby, Inc.

0022-5223/98 \$5.00+ $0 \quad \mathbf{1 2 / 6 / 8 7 2 1 9}$
Neonates and children with congenital heart disNease who undergo cardiac operations may require cardiopulmonary bypass (CPB) during operative repair. Although exposure to this artificial "system" is essential, several organ systems, including the pulmonary system, are adversely affected by CPB. This organ injury is magnified in neonates. ${ }^{1-3}$ The effects of CPB on neonatal pulmonary function are complex. Alterations in pulmonary mechanics, gas exchange, pulmonary artery pressure, surfactant production, and pulmonary vascular resistance (PVR) have been described in neonatal and pediatric patients undergoing $\mathrm{CPB}$. $^{1,4-8}$

Organ-protective strategies have traditionally been targeted at myocardial and cerebral function. With improvements in myocardial and cerebral pro- 
tection, operative techniques, and perioperative care, early neonatal or infant repair is recommended for most repairable congenital heart lesions. ${ }^{9,} 10$ Long-term results are encouraging; however, without a strategy for lung protection, the pulmonary vasculature and parenchyma may suffer severe injury after $\mathrm{CPB}$, resulting in increased morbidity and mortality, abnormal convalescence, and prolonged ventilatory requirements. Many neonates and infants have a prolonged intensive care unit (ICU) admission because of this postoperative respiratory insufficiency. ${ }^{1,9}$ The main determination of the length of stay of infants and children in the ICU is the need for mechanical ventilation.

These pathophysiologic changes that occur in the pulmonary system of neonates and pediatric patients after exposure to CPB also have an impact on the cardiovascular system. ${ }^{4-6,8,11,12}$ The effects of respiratory insufficiency and mechanical ventilation on cardiorespiratory interactions are well described and are of increasing importance after CPB. The overall cardiorespiratory adverse effects of CPB may be significantly reduced if the initial lung injury can be minimized.

The mechanism of the pulmonary vascular and parenchymal injuries is multifactorial. CPB with hypothermia may result in a variety of injuries, including those related to oxygenation/reoxygenation, hypoxemia, ischemia, and reperfusion. Exposure of blood to nonendothelialized surfaces activates the immune system, including the complement cascade. These injuries often result in decreased pulmonary compliance, increased PVR, and, potentially, decreased cardiac output. These abnormalities of cardiorespiratory function may result in decreased oxygen delivery.

Liquid ventilation with perflubron (LiquiVent; Alliance Pharmaceutical Corp., San Diego, Calif.) may be beneficial in treating acute lung injury. ${ }^{13-21}$ The beneficial effects of liquid ventilation include its antiinflammatory properties, alveolar distending properties, surfactant-like function, and oxygen delivery capability. During CPB, the lungs are bypassed and are usually not ventilated. Thus liquid ventilation may provide an opportunity to access and to protect the lungs during $\mathrm{CPB}$. As a result, administering perflubron to the lungs during CPB might benefit the patient by modifying the adverse pulmonary response to bypass.

At present, no clinical data are available on the use of liquid ventilation in association with CPB for cardiac operations. Thus the focus of our study was to define the role of liquid ventilation on cardiac and respiratory function after $\mathrm{CPB}$. We hypothesized that liquid ventilation initiated before CPB would improve post-CPB pulmonary function and cardiac output in a neonatal model of CPB. The beneficial effects of liquid ventilation include exerting effects similar to surfactant, functioning as a liquid positive end-expiratory pressure to reduce atelectasis, providing antiinflammatory properties, and acting as an oxygen carrier at the alveolar level. The physiologic benefits of liquid ventilation would include improved pulmonary compliance, decreased regional hypoxic pulmonary vasoconstriction, improved cardiac output, and increased oxygen delivery.

\section{Materials and methods}

Anesthesia and operation. The operative procedures and animal care were in compliance with the guidelines established by the National Institutes of Health and the Institutional Animal Care and Use Committee of Duke University Medical Center. Twenty neonatal swine (1 week old; 2.0 to $3.4 \mathrm{~kg}$ ) were used in this study. Each animal was premedicated with intramuscular acepromazine maleate (INN: acepromazine) $(1.1 \mathrm{mg} / \mathrm{kg})$ and ketamine $(22 \mathrm{mg} / \mathrm{kg})$. Sodium thiopental $(25 \mathrm{mg} / \mathrm{kg})$ and methylprednisolone sodium succinate (Solu-Medrol) (20 $\mathrm{mg} / \mathrm{kg}$ ) were administered after obtaining intravenous access. The trachea was intubated with a cuffed endotracheal tube compatible with perflubron, and the animal was placed on an SV300 ventilator (Siemens-Elema; Solno, Sweden) in the volume control mode. Initial ventilatory settings included inspired oxygen fraction $\left(\mathrm{FiO}_{2}\right)$, 1.0; delivered tidal volume (measured at the endotracheal tube), $12 \mathrm{ml} / \mathrm{kg}$; positive end expiratory pressure, $3 \mathrm{~cm}$ $\mathrm{H}_{2} \mathrm{O}$; and inspiratory time, 0.65 seconds. The respiratory rate was adjusted to maintain an arterial carbon dioxide tension $\left(\mathrm{PaCO}_{2}\right)$ between 35 and $45 \mathrm{~mm} \mathrm{Hg}$.

Anesthesia was maintained with a continuous infusion of fentanyl. Intermittent boluses of pancuronium bromide were administered for neuromuscular blockade. A femoral artery catheter was placed for systemic blood pressure monitoring and blood sampling. After a median sternotomy, the pericardium was incised, and a pericardial cradle created. An ultrasonic transit-time flow probe (Transonic Systems, Inc., Ithaca, N.Y.) was placed around the pulmonary artery at the level of the right ventricular (RV) outflow tract. Micromanometer pressure catheters (Millar Instruments, Inc., Houston, Tex.) were placed in the right ventricle and in the pulmonary artery at the level of the ultrasonic flow probe.

CPB and liquid ventilation (Fig. 1). The animals randomized to the control group were ventilated conventionally at the settings described. The animals randomized to the intervention group received liquid ventilation before $\mathrm{CPB}$. Perflubron was administered to approximate the functional residual capacity as determined by the presence of perflubron in the endotracheal tube at a positive end-expiratory pressure of $0 \mathrm{~cm} \mathrm{H}_{2} \mathrm{O}$. The perflubron dose was limited to a maximum of $20 \mathrm{ml} / \mathrm{kg}$. The per- 


\section{Protocol}

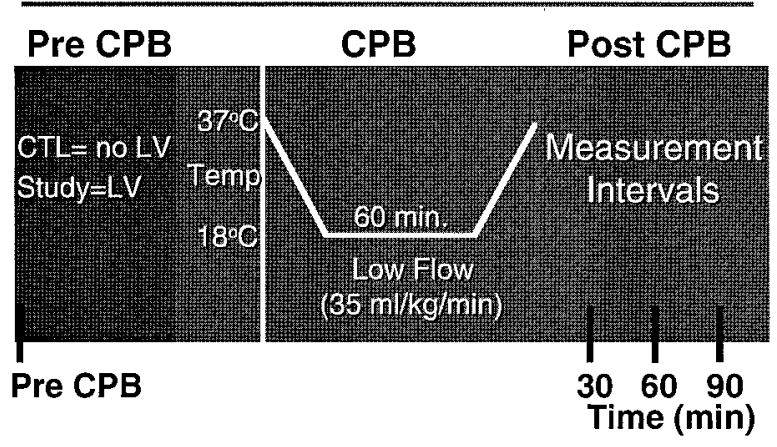

Fig. 1. Diagrammatic representation of the animal protocol. $C P B$, Cardiopulmonary bypass; $C T L$, control animals; $L V$, liquid ventilation.

flubron was administered over 15 to 20 minutes by use of standard technique through the side-port of an adapter on the endotracheal tube. ${ }^{13,15-19}$ Perflubron administration was completed before cannulation for CPB. No further doses of perflubron were administered.

After heparinization (300 units $/ \mathrm{kg}$ ), each piglet was placed on conventional, nonpulsatile CPB. Cannulation was accomplished by placing an $8 \mathrm{~F}$ infant arterial cannula in the ascending aorta and a single $22 \mathrm{~F}$ venous cannula in the right atrium. Each animal was cooled over 20 minutes to a nasopharyngeal temperature of $18^{\circ} \mathrm{C}$. After cooling, the flow was adjusted to $35 \mathrm{ml} / \mathrm{kg}$ per minute for 60 minutes to maintain a mean arterial pressure less than or equal to $45 \mathrm{~mm} \mathrm{Hg}$. During this period of low-flow CPB, the ventilator was set to deliver a constant positive airway pressure of $5 \mathrm{~cm} \mathrm{H} \mathrm{H}_{2} \mathrm{O}$ with the $\mathrm{Fio}_{2}$ decreased to 0.21 . After the 60-minute period of low-flow CPB, the ventilator settings were adjusted to $\mathrm{Fio}_{2}, 1.0$; delivered tidal volume, $12 \mathrm{ml} / \mathrm{kg}$; positive end-expiratory pressure, $5 \mathrm{~cm}$ $\mathrm{H}_{2} \mathrm{O}$; and inspiratory time, 0.65 seconds. After a 20- to 30 -minute period of rewarming, the animals were removed from CPB. All animals in both groups were started on a dopamine infusion at $10 \mu \mathrm{g} / \mathrm{kg}$ per minute at the time of separation from CPB.

Data collection. Data were collected for the control group at baseline before bypass. Baseline data for the liquid ventilation group were obtained at baseline before both CPB and the administration of perflubron. Post-CPB data were collected for both groups at 30,60 , and 90 minutes after separation from CPB.

Measurements. The determination of the pulmonary parenchymal injury consisted of evaluating respiratory mechanics and gas exchange. All respiratory mechanics measurements were obtained using a pneumotachometer and a stand-alone respiratory mechanics monitor (Ventrak, Novametrix Medical Systems; Wallingford, Conn.). Measurements included peak inspiratory pressure, plateau pressure, mean airway pressure, dynamic compliance, and total airways resistance. Static compliance was calculated as delivered tidal volume divided by the difference between the plateau pressure and the positive endexpiratory pressure.
Cardiac output was determined by the ultrasonic pulmonary artery flow probe. Oxygen delivery was determined by the standard calculation of cardiac output $x$ $\left(1.34 \times\right.$ hemoglobin $\times$ oxygen saturation $\left.+0.003 \times \mathrm{Pao}_{2}\right)$.

In addition to the standard measures of pulmonary artery pressure and pulmonary blood flow, the pulmonary vascular injury was assessed by pulmonary input resistance and pulmonary characteristic impedance. To calculate the impedance spectrum, the data sets were individually separated into cardiac cycles and waveform averaged. ${ }^{22}$ Characteristic impedance, which is derived from the impedance spectrum, describes the physical properties of the pulmonary vascular bed and is inversely related to its compliance and cross-sectional area. ${ }^{22-24}$ Characteristic impedance describes the resistance of the larger, proximal pulmonary vessels. In contrast, pulmonary input resistance (mean pulmonary artery pressure/mean pulmonary blood flow) evaluates the entire pulmonary vasculature (large proximal vessels and small distal vessels). ${ }^{22-24}$ The measurements of both pulmonary characteristic impedance and input resistance allow for a comprehensive evaluation of the reactivity of the pulmonary vasculature.

Statistical analysis. The pre-CPB baseline data for each group were compared with the data 30 minutes after CPB by paired $t$ tests. The data at baseline were compared between the two groups by unpaired $t$ tests to ensure appropriate randomization. The post-CPB data $(30,60$, and 90 minutes) were compared between the two groups using a linear regression model of analysis of variance with repeated measures. All data are indicated as mean \pm standard error of the mean.

\section{Results}

At baseline (pre-CPB), the control group $(n=11)$ and the intervention group $(n=9)$ were similar in terms of hemodynamics, gas exchange, pulmonary reactivity, pulmonary compliance, cardiac output, and oxygen delivery (Tables I to III). The average weight of the control animals was $2.70 \pm 0.15 \mathrm{~kg}$ compared with $2.69 \pm 0.13 \mathrm{~kg}$ for the animals receiving liquid ventilation.

The pre-CPB data for both the control and the liquid ventilation groups were compared with the data 30 minutes after separation from $\mathrm{CPB}$ to characterize the effects of $\mathrm{CPB}$ on the pulmonary system and to assess the modification of these effects by liquid ventilation (Tables I and II). Without liquid ventilation, CPB resulted in a significant decrease in cardiac output $(229 \pm 29$ vs $140 \pm 18$ $\mathrm{ml} / \mathrm{min}, p=0.02)$ and oxygen delivery $(3.98 \pm 0.49$ vs $2.44 \pm 0.30 \mathrm{~L} / \mathrm{min}, p=0.02)$ while increasing input pulmonary resistance $(4434 \pm 527$ vs $22,522 \pm$ 4713 dynes $\left.\cdot \mathrm{sec} \cdot \mathrm{cm}^{5}, p=0.004\right)$ and characteristic impedance $(794 \pm 78$ vs $1339 \pm 219$ dynes $\left.\cdot \mathrm{sec} \cdot \mathrm{cm}^{5}, p=0.05\right)$. Static compliance decreased in the control group with CPB $(1.23 \pm 0.11$ vs $0.84+0.06 \mathrm{ml} / \mathrm{cm} \mathrm{H}_{2} \mathrm{O}$ per kilogram, $p=0.004$ ). 
Table I. Pulmonary reactivity, cardiac output, and oxygen delivery

\begin{tabular}{clcccc}
\hline Time & Group & $\begin{array}{c}\text { Rin } \\
\left(d-s / \mathrm{cm}^{5}\right)\end{array}$ & $\begin{array}{c}\mathrm{Zo} \\
\left(d-\mathrm{s} / \mathrm{cm}^{5}\right)\end{array}$ & $\begin{array}{c}\mathrm{CO} \\
(\mathrm{mL} / \mathrm{min})\end{array}$ & $\begin{array}{c}\mathrm{DO}_{2} \\
(\mathrm{~L} / \mathrm{min})\end{array}$ \\
\hline \multirow{2}{*}{ pre-CPB } & CTL & $4434 \pm 527$ & $794 \pm 78$ & $229 \pm 29$ & $3.98 \pm 0.49$ \\
& LV & $4294 \pm 537$ & $801 \pm 113$ & $223 \pm 22$ & $3.90 \pm 0.39$ \\
$30 \mathrm{~min}$ & CTL & $22,522 \pm 4713^{*}$ & $1339 \pm 219^{*}$ & $140 \pm 18^{*}$ & $2.44 \pm 0.30^{*}$ \\
& LV & $10,850 \pm 805 \dagger+$ & $913 \pm 59 \dagger$ & $215 \pm 18 \dagger$ & $3.66 \pm 0.28 \dagger+$ \\
$60 \mathrm{~min}$ & CTL & $17,865 \pm 2517^{*}$ & $1228 \pm 113^{*}$ & $153 \pm 19^{*}$ & $2.65 \pm 0.32^{*}$ \\
& LV & $12,045 \pm 1896 \dagger+$ & $744 \pm 52 \dagger$ & $190 \pm 21 \dagger+$ & $3.23 \pm 0.35 \ddagger$ \\
& CTL & $18,738 \pm 2790^{*}$ & $1114 \pm 125^{*}$ & $146 \pm 15^{*}$ & $2.55 \pm 0.27^{*}$ \\
& LV & $13,793 \pm 1852 \dagger+$ & $922 \pm 136 \dagger$ & $170 \pm 12 \dagger \neq$ & $2.92 \pm 0.21 \ddagger$ \\
\hline
\end{tabular}

$C T L$, Control group; $L V$, liquid ventilation group; Rin, input pulmonary vascular resistance; $Z o$, characteristic impedance; $C O$, cardiac output; $D O_{2}$ oxygen delivery.

${ }^{*} p<0.05$ vs pre-CPB CTL; $\dagger p<0.05$ vs CTL; $\ddagger p<0.05$ vs pre-CPB LV.

Table II. Gas exchange, airway pressures, pulmonary compliance, and airways resistance

\begin{tabular}{|c|c|c|c|c|c|c|c|c|c|}
\hline Time & Group & $p H$ & $\begin{array}{c}\mathrm{PaCO}_{2} \\
\text { (torr) }\end{array}$ & $\begin{array}{l}\mathrm{PaO}_{2} \\
\text { (torr) }\end{array}$ & $P I P$ & $\begin{array}{c}\mathrm{MAP} \\
\left(\mathrm{cm} \mathrm{H}_{2} \mathrm{O}\right)\end{array}$ & $\begin{array}{c}\text { Cstat } \\
\left(\mathrm{ml} / \mathrm{cm} \mathrm{H}_{2} \mathrm{O} / \mathrm{kg}\right)\end{array}$ & $\begin{array}{c}C d y n \\
\left(\mathrm{ml} / \mathrm{cm} \mathrm{H} \mathrm{H}_{2} \mathrm{O} / \mathrm{kg}\right)\end{array}$ & $\begin{array}{c}T A R \\
\left(\mathrm{~cm} \mathrm{H}_{2} \mathrm{O} / \mathrm{L} / \mathrm{s}\right)\end{array}$ \\
\hline \multirow[t]{2}{*}{ pre-CPB } & CTL & $7.42 \pm 0.01$ & $42 \pm 1$ & $457 \pm 26$ & $16.8 \pm 0.8$ & $4.7 \pm 0.2$ & $1.23 \pm 0.11$ & $1.33 \pm 0.16$ & $113 \pm 4$ \\
\hline & LV & $7.44 \pm$ & $38 \pm 1$ & $472 \pm 22$ & .9 & $4.6 \pm 0.2$ & $1.36=$ & $1.32=$ & \\
\hline \multirow[t]{2}{*}{$30 \mathrm{~min}$} & CTL & $7.39 \pm 0.02$ & $44 \pm 2$ & $456 \pm 41$ & $23.5 \pm 1.1$ & $7.6 \pm 0.2$ & $0.84 \pm 0.06^{*}$ & $0.95 \pm 0.08$ & $138 \pm 5$ \\
\hline & LV & $7.37 \pm 0.02$ & $44 \pm 1$ & $322 \pm 37+t$ & $22.0 \pm 1.0$ & $7.9 \pm 0.2$ & $1.08 \pm 0.11 \dagger+$ & $0.95 \pm 0.09$ & $133 \pm 4$ \\
\hline \multirow[t]{2}{*}{$60 \mathrm{~min}$} & CTL & $7.36 \pm 0.02$ & $39 \pm 4$ & $439 \pm 41$ & $24.3 \pm 1.2$ & $7.8 \pm 0.2$ & $0.81 \pm 0.07^{*}$ & $0.89 \pm 0.07$ & $141 \pm 5$ \\
\hline & LV & $7.38 \pm 0.01$ & $44 \pm 2$ & $317 \pm 31 \dagger \ddagger$ & $22.0 \pm 1.0$ & $8.0 \pm 0.2$ & $1.10 \pm 0.11 \dagger+$ & $0.95 \pm 0.08$ & $134 \pm 5$ \\
\hline \multirow[t]{2}{*}{$90 \mathrm{~min}$} & CTL & $7.39 \pm 0.01$ & $42 \pm 1$ & $448 \pm 32$ & $25.1 \pm 1.1$ & $7.9 \pm 0.2$ & $0.75 \pm 0.06^{*}$ & $0.84 \pm 0.06$ & $147 \pm 7$ \\
\hline & LV & $7.40 \pm 0.02$ & $42 \pm 1$ & $359 \pm 37 \dagger t$ & $22.9 \pm 1.0$ & $8.1 \pm 0.2$ & $1.02 \pm 0.11 \dagger+$ & $0.90 \pm 0.08$ & $137 \pm 5$ \\
\hline
\end{tabular}

$C T L$, control group; $L V$, liquid ventilation group; PIP, peak inspiratory pressure; $M A P$, mean airway pressure; Cstat, static compliance; $C d y n$, dynamic compliance; TAR, total airways resistance. Mean \pm SEM.

${ }^{*} p<0.05$ vs pre-CPB CTL; $\dagger p<0.05$ vs CTL; $\ddagger p<0.05$ vs pre-CPB LV.

In animals receiving liquid ventilation, $\mathrm{CPB}$ resulted in a significant increase in input pulmonary resistance $\left(4294 \pm 537\right.$ vs $10,850 \pm 805$ dynes $\cdot \mathrm{sec} \cdot \mathrm{cm}^{5}$, $p=0.001)$ and decrease in static compliance $(1.36 \pm$ 0.15 vs $1.08 \pm 0.11 \mathrm{ml} / \mathrm{cm} \mathrm{H}_{2} \mathrm{O}$ per kilogram, $p=$ 0.001 ) however, no significant changes were observed in cardiac output $(223 \pm 22$ vs $215 \pm 18$ $\mathrm{ml} / \mathrm{min})$, oxygen delivery ( $3.90 \pm 0.39$ vs $3.66 \pm 0.28$ $\mathrm{L} / \mathrm{min})$, or characteristic impedance $(801 \pm 113$ vs $913 \pm 59$ dynes $\left.\cdot \mathrm{sec} \cdot \mathrm{cm}^{5}\right)$.

The post-CPB data $(30,60$, and 90 minutes) were compared between the two groups using a linear regression model of analysis of variance with repeated measures at 30,60, and 90 minutes after $\mathrm{CPB}$ to characterize the degree of lung protection offered by the liquid ventilation. At 30 minutes after separation from $\mathrm{CPB}$, animals receiving liquid ventilation had increased cardiac output (54\%), increased oxygen delivery $(50 \%)$, decreased input pulmonary resistance $(52 \%)$, decreased characteristic impedance $(32 \%)$, and improved static compliance (26\%) compared with control animals not receiving liquid ventilation. These statistically and clinically significant differences were maintained throughout the 90-minute data acquisition period, although to a lesser degree (Tables I and II).

At baseline and at 30, 60, and 90 minutes after separation from CPB, no statistically or clinically significant differences were observed in $\mathrm{pH}, \mathrm{PacO}_{2}$, systemic pressures, mean airway pressure, or total airways resistance (Tables II and III). Oxygenation was higher after $\mathrm{CPB}$ in the control group but not to a clinically significant degree. At baseline and at 30 minutes after $\mathrm{CPB}$, peak inspiratory pressure and dynamic compliance were similar. However, at 60 and 90 minutes after CPB, peak inspiratory pressure trended lower and dynamic compliance trended higher in the group treated with liquid ventilation (Table II).

\section{Discussion}

Neonatal and pediatric patients with respiratory dysfunction resulting from $\mathrm{CPB}$ have a significantly increased morbidity and mortality. ${ }^{1}$ The pulmonary injury that occurs in these patients and the effects of this injury on cardiac function are not well understood. Improving lung function and lessening the sequelae associated with respiratory insufficiency in the immediate post-CPB period is essential in re- 
Table III. Hemodynamics

\begin{tabular}{clccc}
\hline Time & Group & $\begin{array}{c}\text { SBP } \\
(\mathrm{mm} \mathrm{Hg})\end{array}$ & $\begin{array}{c}\text { MBP } \\
(\mathrm{mm} \mathrm{Hg})\end{array}$ & $\begin{array}{c}\mathrm{DBP} \\
(\mathrm{mm} \mathrm{Hg})\end{array}$ \\
\hline pre-CPB & CTL & $81 \pm 5$ & $60 \pm 4$ & $48 \pm 4$ \\
& LV & $74 \pm 5$ & $55 \pm 5$ & $44 \pm 5$ \\
$30 \mathrm{~min}$ & CTL & $74 \pm 5$ & $53 \pm 4$ & $39 \pm 3$ \\
& LV & $83 \pm 6$ & $57 \pm 5$ & $41 \pm 4$ \\
$60 \mathrm{~min}$ & CTL & $66 \pm 6^{*}$ & $48 \pm 4^{*}$ & $37 \pm 3^{*}$ \\
& LV & $65 \pm 3 \dagger$ & $44 \pm 2 \dagger$ & $32 \pm 3 \dagger$ \\
$90 \mathrm{~min}$ & CTL & $62 \pm 5^{*}$ & $47 \pm 3^{*}$ & $36 \pm 4^{*}$ \\
& LV & $67 \pm 4 \dagger$ & $46 \pm 2 \dagger$ & $33 \pm 3 \dagger$
\end{tabular}

$\overline{C T L}$, Control group; $L V$, liquid ventilation group; $S B P$, systolic systemic blood pressure; $M B P$, mean systemic blood pressure; $D P B$, diastolic systemic blood pressure. Mean \pm SEM.

${ }^{*} p<0.05$ vs pre-CPB CTL; $\dagger p<0.05$ vs pre-CPB LV.

ducing morbidity and mortality. This is especially important in neonates because the lung injury that occurs in these patients is particularly severe. ${ }^{1,25}$ Liquid ventilation appears to be quite promising in improving lung function during acute lung disease. ${ }^{13-21}$ If liquid ventilation improves pulmonary parenchymal mechanics, pulmonary vascular mechanics, and cardiac output after CPB, then overall cardiorespiratory performance will improve.

After operation for congenital heart disease, pulmonary insufficiency can significantly alter cardiovascular performance. These changes may be significant and cause abnormal ventricular function in neonates and young children because the required repair can disrupt the normal myocardial architecture, resulting in direct myocardial injury, whereas $\mathrm{CPB}$ contributes to myocardial edema and changes in loading conditions. ${ }^{9,10}$ In the postoperative period, the right ventricle may be unable to increase its work load when presented with increased RV afterload resulting from pulmonary vasoconstriction. In addition, a deterioration in respiratory parenchymal function after bypass may result in the need for increased airway pressures. This increased ventilatory support may further compromise RV function by limiting RV preload and/or further increasing RV afterload. Decreased RV output would decrease left ventricular preload and therefore decrease systemic cardiac output.

Mechanisms of CPB-induced lung injury. The pathophysiology of the CPB-induced pulmonary injury is not well understood. This pulmonary injury is most probably multifactorial with causes including oxygenation/reoxygenation, hypoxemia, ischemia, reperfusion, and surfactant dysfunction. . $^{5}, 11,12,26-29$ A systemic inflammatory response occurs during CPB as blood contacts nonphysiologic surfaces. ${ }^{5,11,26-28}$
This inflammatory response is characterized by complement activation, leukocyte degranulation, neutrophil activation, increased capillary permeability, and membrane injury. ${ }^{5,11,26-28}$ Complement activation may compromise lung function by altering airways resistance and pulmonary compliance. ${ }^{5}$ Surfactant function has been shown to decrease with CPB in children. ${ }^{29}$ Surfactant dysfunction correlates with increased atelectasis and decreased pulmonary compliance. Hypothermia and nonpulsatile perfusion may induce pulmonary injury by altering the patterns of pulmonary blood flow. $4,5,11$

Sequelae of the CPB-induced pulmonary injury. Management of the pulmonary insufficiency during the postoperative period requires an understanding of the physiologic consequences of CPB. Capillary leak with alveolar edema resulting from pulmonary endothelial cell injury reduces pulmonary compliance and functional residual capacity and increases the alveolar-arterial oxygen gradient ${ }^{7,8,30}$ In addition, atelectasis causes ventilation-perfusion mismatch, the development of intrapulmonary shunting, and pulmonary vasoconstriction that manifests clinically as increased PVR, increased pulmonary artery pressure, decreased arterial saturation, and reduced arterial oxygen content. ${ }^{2,3,7,31}$ Therapy for pediatric patients with pulmonary insufficiency is directed at reducing and/or preventing endothelial cell injury and alveolar collapse.

Our study data confirm these bypass-associated vascular and parenchymal pulmonary injuries. The increases in input pulmonary resistance and characteristic impedance were associated with a decrease in cardiac output and oxygen delivery. Decreased static compliance supports the presence of the parenchymal injury.

Liquid ventilation. Liquid ventilation has the potential to be beneficial in both clinical and animal evaluations of acute lung injury. ${ }^{13,21}$ In liquid ventilation perflubron is instilled into the injured lungs at a volume that approximates the functional residual capacity of the lungs. ${ }^{13}$ The patient is then conventionally ventilated. Perflubron may have antiinflammatory properties and may eliminate the air-fluid interface, decreasing surface tension and providing a surfactant-like effect. In addition, the presence of liquid in the alveoli maintains alveolar patency by exerting a continuous alveolar distending pressure during the expiratory phase ("liquid positive end-expiratory pressure"). These effects of perflubron would decrease alveolar atelectasis and maintain the functional residual capacity of the 
lungs. ${ }^{32}$ Thus liquid ventilation should improve pulmonary compliance while reducing PVR and improving cardiac output and oxygen delivery. ${ }^{13-21}$

In our study, the use of liquid ventilation improved post-bypass pulmonary function. Therefore the degree of lung injury seen after CPB may have been less in the animals receiving perflubron therapy than in the control animals. After CPB, the animals receiving liquid ventilation did have a modest increase in input pulmonary resistance and decrease in static compliance. However, a significant change in cardiac output, oxygen delivery, or characteristic impedance was not observed. When comparing the liquid ventilation group with the control group, a significant reduction in pulmonary parenchymal and vascular injury was seen at 30,60 , and 90 minutes after CPB. These data suggest that liquid ventilation may have helped to protect the lungs from the deleterious effects of CPB in this neonatal model.

An improvement in static compliance implies the ability to deliver the same tidal volume at a lower airway pressure. Postoperatively, this decrease in airway pressure should correlate with a decreased risk for barotrauma, potentially a decreased length of mechanical ventilation, and an improvement in cardiorespiratory interactions.

Although the exact mechanisms of the pulmonary vascular protection offered by liquid ventilation remain uncertain, the relationship of various physiologic changes can be hypothesized. Some combination of the beneficial effects of liquid ventilation, including its antiinflammatory properties, alveolar distending properties, surfactant-like function, and oxygen delivery capability, resulted in a decrease in pulmonary reactivity. This improvement was demonstrated by a decrease in both input resistance and characteristic impedance. Presumably, this decrease in the afterload to the right ventricle resulted in improved RV function and, subsequently, increased global cardiac output. The increased cardiac output resulted in a clinically significant improvement in oxygen delivery.

Potential adverse effects. Liquid ventilation is not without theoretical risks. ${ }^{13-19,33}$ The presence of perflubron in the alveolar space may result in adverse effects on cardiorespiratory function. As a liquid, perflubron is an excellent carrier of oxygen; however, it is not as efficient as gas in transporting oxygen. When perflubron is placed in the alveoli, the maximum alveolar-arterial oxygen tension obtainable is 350 to $400 \mathrm{~mm} \mathrm{Hg}$ versus $713 \mathrm{~mm} \mathrm{Hg}$ for a gas at standard temperature and pressure. ${ }^{32}$ This results in an obligatory alveolar-arterial oxygen gradient when perflubron is instilled into normal lungs. Thus in normal lungs this has the potential to decrease the arterial oxygen content and lead to hypoxemia. However, in the early operative period, ventilating a patient with normal lung function and without a right-to-left shunt with an $\mathrm{Fio}_{2}$ of 1.0 would result in a arterial oxygen tension of 300 to $400 \mathrm{~mm} \mathrm{Hg}$, and this should not pose any risk to the patient. If the patient does have underlying lung disease, previous animal studies have demonstrated that when lung injury is present perflubron increases the systemic arterial oxygen content compared with conventional ventilation at similar settings. ${ }^{13-19,33} \mathrm{In}$ situations in which the concern over possible hypoxia exists, the perflubron may be administered immediately after cannulation for bypass.

Theoretically, perflubron may alter cardiorespiratory performance by altering intrathoracic pressure. When perflubron is instilled into the lungs, the weight of the liquid $(1.92 \mathrm{gm} / \mathrm{ml})$ may increase intrathoracic pressure. ${ }^{32}$ This increase in intrathoracic pressure may limit preload and decrease cardiac output by decreasing RV filling. Our data do not support this theoretical risk. In addition, perflubron has the potential to expand the alveolus and compress the pulmonary vasculature. Potentially, this may lead to an increase in pulmonary artery resistance and a worsening of $\mathrm{RV}$ function if $\mathrm{RV}$ afterload is significantly increased. The results from this study indicate that PVR and cardiac output are, in fact, improved with perflubron therapy. Therefore the theoretical concern that perflubron may adversely affect cardiorespiratory performance does not seem valid under the conditions of this study.

Limitations of the study. Perflubron has been shown to evaporate over time. ${ }^{13,32}$ Therefore the initial dose of perflubron may be inadequate to maintain the improvement in lung function hypothesized. Supplemental doses of perflubron may be needed; however, the effects of maintaining a constant volume of perflubron in the lungs by providing additional dosing was not the intent of this study. Additionally, this study was an acute study and did not answer the question of the effects of liquid ventilation on the length of mechanical ventilation.

By administering the perflubron before $\mathrm{CPB}$, it cannot be determined from our data whether liquid ventilation prevented the pulmonary lung injury or treated the lung injury as it was occurring. In either case, the net result was improved pulmonary function with liquid ventilation after bypass. Future 
experiments with perflubron dosing before and after bypass can be performed to determine whether liquid ventilation prevents or treats the lung injury associated with $\mathrm{CPB}$ and to identify the exact mechanisms involved.

Our evaluation of liquid ventilation immediately after bypass represents a time period of increased vulnerability for the neonate because the cardiorespiratory abnormalities that develop are at their peak. Data obtained during this "high-risk" phase can be extrapolated to clinical practice and are essential to design future clinical and laboratory investigations. The long-term effects of liquid ventilation may be a subject of future research.

We have demonstrated that the lung protection strategy of liquid ventilation improved pulmonary vascular and parenchymal function and cardiac output in a neonatal model of $\mathrm{CPB}$. The morbidity associated with $\mathrm{CPB}$ may be significantly reduced if the adverse pulmonary sequelae of CPB can be diminished. Liquid ventilation may become an important technique for protecting the lungs from the deleterious effects of CPB.

\section{REFERENCES}

1. Kocis K, Meliones JN, Dekeon MK, Callow LB, Lupinetti FM, Bove EL. High frequency jet ventilation for respiratory failure after congenital heart surgery. Circulation 1992; 86(Suppl):II127-32.

2. Kirshbom PM, Jacobs MT, Tsui SS, DiBernardo LR, Meliones JN, Schwinn DA, et al. Effects of cardiopulmonary bypass and circulatory arrest on endothelium-dependent vasodilatation in the lung. J Thorac Cardiovasc Surg 1996; 111:1248-56.

3. Skaryak LA, Lodge AJ, Kirshbom PM, DiBernardo LR, Wilson BG, Meliones JN, et al. Low-flow cardiopulmonary bypass produces greater pulmonary dysfunction than circulatory arrest. Ann Thorac Surg 1996;62:1284-8.

4. Deal CW, Warden JC, Monk I. Effect of hypothermia on lung compliance. Thorax 1970;25:105-9.

5. Howard RJ, Crain C, Franzini DA, Hood CI, Hugli TE. Effects of cardiopulmonary bypass on pulmonary leukostasis and complement activation. Arch Surg 1988;123:1496-501.

6. Meliones JN, Gaynor JW, Wilson BG, Kern FH, Schulman SR, Shearer IR, et al. Modified ultrafiltration reduces airway pressures and improves lung compliance after congenital heart surgery. J Am Coll Cardiol 1995;Special Issue;271A.

7. Jenkins J, Lynn A, Edmonds J, Barker G. Effects of mechanical ventilation on cardiopulmonary function in children after open-heart surgery. Crit Care Med 1985;13:77-80.

8. Journois D, Pouard P, Greeley WJ, Mauriat P, Vouhe P, Safran D. Hemofiltration during cardiopulmonary bypass in pediatric cardiac surgery: effects on hemostasis, cytokines, and complement components. Anesthesiology 1994; 81:1181-9.

9. Groh MA, Meliones JN, Bove EL, Kirklin JW, Blackstone EH, Lupinetti FM, et at. Repair of tetralogy of Fallot in infancy: effect of pulmonary artery size on outcome. Circulation 1991:84(Suppl):III206-12.

10. Lupinetti FM, Bove EL, Minich LL, Snider AR, Callow LB, Meliones JN, et al. Intermediate-term survival and functional results after arterial repair for transposition of the great arteries. J Thorac Cardiovasc Surg 1992;103:421-7.

11. Bui KC, Hammerman C, Hirschl RB, Hill V, Snedecor SM, Schumacher R, et al. Plasma prostanoids in neonates with pulmonary hypertension treated with conventional therapy and with extracorporeal membrane oxygenation. J Thorac Cardiovasc Surg 1991;101:973-83.

12. Zapol WM, Peterson MB, Wonders TR, Kong D, Watkins WD. Plasma thromboxane and prostacyclin metabolites in sheep partial cardiopulmonary bypass. Trans Am Soc Artif Intern Organs 1980;26:556-60.

13. Fuhrman BP, Paczan PR, DeFrancisis M. Perfluorocarbon associated gas exchange. Crit Care Med 1991;19:712-23.

14. Shaffer TH, Ferguson JD, Koen PA, Moskowitz GD. Pulmonary lavage in preterm lambs. Pediatr Res 1978;12:695-8.

15. Greenspan JS, Wolfson MR, Rubenstein SD, Shaffer TH. Liquid ventilation of human preterm neonates. J Pediatr 1990;117:106-11.

16. Calderwood HW, Modell JH, Ruiz BC, Brogdon JE, Wood CI. Pulmonary lavage with liquid fluorocarbon in a model of pulmonary edema. Anesthesiology 1973;38:141-4.

17. Salman NH, Fuhrman BP, Steinhorn DM, Papo MC, Hernan $\mathrm{LJ}$, Leach $\mathrm{CL}$, et al. Prolonged studies of perfluorocarbon associated gas exchange and of the resumption of conventional mechanical ventilation. Crit Care Med 1995;23:919-24.

18. Shaffer TH, Lowe CA, Bhutani VK, Douglas PR. Liquid ventilation: effects on pulmonary function in distressed meconium-stained lambs. Pediatr Res 1984;18:47-52.

19. Leach CL, Fuhrman BP, Morin FC III, Rath MG. Perfluorocarbon-associated gas exchange (PAGE) in respiratory distress syndrome: a prospective, randomized, controlled study. Crit Care Med 1993;21:1270-8.

20. Tutuncu AS, Faithfull NS, Lachmann B. Comparison of ventilatory support with intratracheal perfluorocarbon administration and conventional mechanical ventilation in animals with acute respiratory failure. Am Rev Respir Dis 1993; 148:785-92.

21. Hirschl RB, Pranikoff T, Wise C, Overbeck MC, Gauger P, Schreiner RJ, et al. Initial experience with partial liquid ventilation in adult patients with the acute respiratory distress syndrome. JAMA 1996;275:383-9.

22. Milnor WR. Hemodynamics. 2nd ed. Baltimore: Williams \& Wilkins; 1989. p. 167-283.

23. Meyers CH, Purut CM, D'Amico TA, Smith PK, Sabiston DC Jr, Van Trigt P. Pulmonary arterial impedance after single lung transplantation. J Surg Res 1992;52:459-65.

24. Hillman ND, Cheifetz IM, Craig DM, Smith PK, Ungerleider $\mathrm{RM}$, Meliones JN. Inhaled nitric oxide, right ventricular efficiency, and pulmonary vascular mechanics: selective vasodilatation of small pulmonary vessels during hypoxic pulmonary vasoconstriction. J Thorac Cardiovasc Surg 1997. In press.

25. Meliones JN, Custer JC, Moler FW, Snedecor SM, Bove EL, Bartlett RH. Extracorporeal life support for cardiac assist in pediatric patients: review of ELSO registry data. Circulation 1991:84(Suppl):III168-72.

26. Tonz M, Mihaljevic T, von Segesser LK, Fehr J, Schmid ER, 
Turina MI. Acute lung injury during cardiopulmonary bypass. Are the neutrophils responsible? Chest 1995;108:1551-6.

27. Casey L. Role of cytokines in the pathogenesis of cardiopulmonary-induced multisystem organ failure. Ann Thorac Surg 1993;56:592-96.

28. Ihnken K, Morita K, Buckberg GD, Matheis G, Sherman MP, Allen BS, et al. Studies of hypoxemic/reoxygenation injury without aortic clamping. J Thorac Cardiovasc Surg 1995;110:1171-81.

29. McGowan FX Jr, Ikegami M, Del Nido PJ, Motoyama EK, Kurland G, Davis PJ, et al. Cardiopulmonary bypass significantly reduces surfactant activity in children. J Thorac Cardiovasc Surg 1993;106;968-77.

30. Cheifetz IM, Black DR, Craig DM, Kern FH, Smith PK, Meliones IN. Nitric oxide improves transpulmonary vascular mechanics but does not change intrinsic right ventricular contractility in an acute respiratory distress syndrome model with permissive hypercapnia. Crit Care Med 1996;24:1554-61.

31. Kirshbom PM, Tsui S, DiBernardo LR, Meliones JN, Schwinn DA, Ungerleider RM, et al. Pulmonary vascular endothelium is capable of producing nitric oxide after cardiopulmonary bypass and circulatory arrest. J Am Coll Cardiol 1995;Special Issue:200A-1A.

32. Sargent JW, Sefel RJ. Properties of perfluorinated liquids. Fed Proc 1970;29:1699-703.

33. Fuhrman BP, Meliones JN, Toro-Figueroa LO, Curtis SE, Thompson AE, Hirschl RB, et al. Partial liquid ventilation with perflubron: a pilot safety and efficacy study in children with ARDS [abstract]. Crit Care Med 1996;24:A150.

\section{Discussion}

Dr. John E. Mayer (Boston, Mass.). In reviewing the manuscript, I must say that several questions occurred to me and I have several comments. As I am sure you know, the relationship between pulmonary blood flow and PVR and pulmonary impedance is complicated, and it is clear that one and the other can clearly interrelate. It can be hard sometimes to separate cause from effect. In the discussion of your manuscript you hypothesize that it is the lower impedance to pulmonary blood flow that resulted in increased RV output and cardiac output. So my first question is, do you have data on RV filling pressures, $\mathrm{RV}$ ejection fraction, RV end-diastolic or end-systolic volumes to support this hypothesis that it is the lower resistance or impedance that resulted in improved RV function?

The second question centers around the lung mechanics that you observed in the treated group versus the untreated group. Because the static compliance was better in the treated animals but the $\mathrm{Pco}_{2}$ was the same in each of the two groups, it seems that the ventilatory management would have to have been altered to keep those same parameters. I wonder whether you could comment on how you think the compliance changes affected the pulmonary hemodynamic parameters that you measured. Along those same lines, clearly some relationship exists between PVR parameters and lung volumes, and traditionally it has been taught that lowest PVR occurs at functional residual capacity. So I wonder whether you might tell us if you measured any lung volume parameters, such as functional residual capacity, in your treated and untreated animals and if you have any idea where you were operating in the range between residual volume and total lung capacity.

The last question that I have relates to the hypothesis that somehow pulmonary vascular endothelial function is preserved. I wonder whether you have done any studies to demonstrate any differences in pulmonary endothelial function or whether you have any evidence that the perflubron is actually absorbed intravascularly and therefore would be a way that pulmonary vascular endothelial protection might be present.

Dr. Cheifetz. Thank you, Dr. Mayer, for reviewing the manuscript and providing some very thoughtful questions.

In terms of the RV filling pressure, we have data that demonstrate that RV end-diastolic pressures were maintained constant throughout the protocol. This was our best approximation of preload. In addition, the volume management of the animals was the same for both groups. So to the best that we can determine from our data, the preload was identical between the two groups. Therefore our assumption is that the improvement in cardiac output is a result of the decrease in afterload in the liquid ventilation group compared with the control group.

Discussing lung mechanics in more detail, $\mathrm{PcO}_{2}$ was maintained identically between the two groups by maintaining the same tidal volume between the control group and the liquid ventilation group. The improvement in static compliance occurs because the plateau pressure is actually lower in the liquid-treated animals for the same tidal volume. So, we see an improvement in lung mechanics while maintaining the same tidal volume and, therefore, the same $\mathrm{PCO}_{2}$.

In terms of the relationship between the plateau pressure, which is decreased in the liquid-treated animals compared with the control animals, and PVR, we have not done any specific correlations between these values. However, the changes in plateau pressures are small and probably do not relate to a large degree to the changes in PVR.

Discussing lung volumes in more detail, in the liquidtreated animals the perflubron was dosed to functional residual capacity using standard technique that has been performed in both clinical and in animal studies. Our best assumption on the basis of prior studies, is that the liquid animals were maintained at functional residual capacity. In the control animals we did not perform any determinations of lung volume. I do not know whether these animals were functioning at or below functional residual capacity. However, for the purposes of this study we were attempting to determine the difference between liquid and control animals knowing that the liquid-treated animals would probably be functioning at slightly higher lung volumes.

Last, in terms of the endothelial function, in this first pilot study we did not specifically test any markers of endothelial cell injury. However, this topic is a central component to our follow-up studies. We are attempting to determine how much of an antiinflammatory effect the perflubron does have in this animal model and how much improvement we can see, simply because perflubron has some antiinflammatory properties. There is minimal absorption of perflubron intravascularly and that exact amount is still uncertain in this animal model. 